University of Wollongong

Research Online

Australian Institute for Innovative Materials -

Papers

Australian Institute for Innovative Materials

$1-1-2017$

High-Performance Hydrogen Storage Nanoparticles Inside Hierarchical

Porous Carbon Nanofibers with Stable Cycling

\author{
Guanglin Xia \\ University of Wollongong, Fudan University, gx168@uowmail.edu.au \\ Xiaowei Chen \\ Jimei University \\ Yan Zhao \\ Fudan University \\ Xingguo Li \\ Peking University \\ Zaiping Guo \\ University of Wollongong, zguo@uow.edu.au
}

See next page for additional authors

Follow this and additional works at: https://ro.uow.edu.au/aiimpapers

Part of the Engineering Commons, and the Physical Sciences and Mathematics Commons

Research Online is the open access institutional repository for the University of Wollongong. For further information contact the UOW Library: research-pubs@uow.edu.au 


\title{
High-Performance Hydrogen Storage Nanoparticles Inside Hierarchical Porous Carbon Nanofibers with Stable Cycling
}

\author{
Abstract \\ An effective route based on space-confined chemical reaction to synthesize uniform Li2Mg(NH)2 \\ nanoparticles is reported. The hierarchical pores inside the one-dimensional carbon nanofibers (CNFs), \\ induced by the creation of well-dispersed Li3N, serve as intelligent nanoreactors for the reaction of Li3N \\ with Mg-containing precursors, resulting in the formation of uniformly discrete $\mathrm{Li} 2 \mathrm{Mg}(\mathrm{NH}) 2$ \\ nanoparticles. The nanostructured $\mathrm{Li} 2 \mathrm{Mg}(\mathrm{NH}) 2$ particles inside the CNFs are capable of complete \\ hydrogenation and dehydrogenation at a temperature as low as $105^{\circ} \mathrm{C}$ with the suppression of ammonia \\ release. Furthermore, by virtue of the nanosize effects and space-confinement by the porous carbon \\ scaffold, no degradation was observed after 50 de/rehydrogenation cycles at a temperature as low as \\ $130{ }^{\circ} \mathrm{C}$ for the as-prepared $\mathrm{Li} 2 \mathrm{Mg}(\mathrm{NH}) 2$ nanoparticles, indicating excellent reversibility. Moreover, the \\ theoretical calculations demonstrate that the reduction in particle size could significantly enhance the $\mathrm{H} 2$ \\ sorption of $\mathrm{Li} 2 \mathrm{Mg}(\mathrm{NH}) 2$ by decreasing the relative activation energy barrier, which agrees well with our \\ experimental results. This method could represent an effective, general strategy for synthesizing \\ nanoparticles of complex hydrides with stable reversibility and excellent hydrogen storage performance. \\ Disciplines \\ Engineering | Physical Sciences and Mathematics

\section{Publication Details} \\ Xia, G., Chen, X., Zhao, Y., Li, X., Guo, Z., Jensen, C. M., Gu, Q. \& Yu, X. (2017). High-Performance Hydrogen \\ Storage Nanoparticles Inside Hierarchical Porous Carbon Nanofibers with Stable Cycling. ACS Applied \\ Materials and Interfaces, 9 (18), 15502-15509.

\section{Authors} \\ Guanglin Xia, Xiaowei Chen, Yan Zhao, Xingguo Li, Zaiping Guo, Craig Jensen, Qinfen Gu, and Xuebin Yu
}




\section{High-Performance Hydrogen Storage Nanoparticles}

\section{Inside Hierarchical Porous Carbon Nanofibers with}

\section{Stable Cycling}

Guanglin Xia, ${ }^{\dagger,}$ Xiaowei Chen,${ }^{\S}$ Yan Zhao,${ }^{\dagger}$ Xingguo Li, ${ }^{\#}$ Zaiping Guo,,${ }^{, \ddagger}$ Craig M. Jensen, $\|$ Qinfen $G u,{ }^{\perp}$ and Xuebin $Y u^{*, \dagger}$

${ }^{\dagger}$ Department of Materials Science, Fudan University, Shanghai 200433, China.

Institute for Superconducting and Electronic Materials, University of Wollongong, North Wollongong, NSW 2522, Australia.

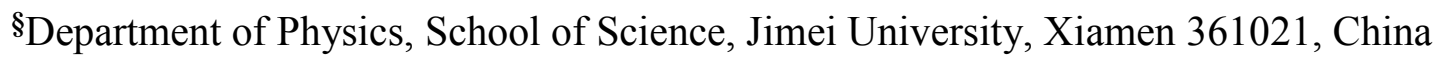

${ }^{\#}$ College of Chemistry and Molecular Engineering, Peking University, Beijing, 100871, China

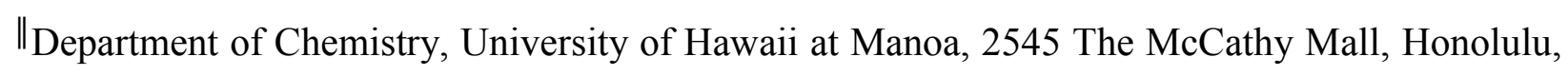
Hawaii 96822-2275, USA

${ }^{\perp}$ Australian Synchrotron, Clayton 3168, Australia

KEYWORDS: nanoparticles, hydrogen storage, amide, carbon nanofibers, cycle. 
ABSTRACT: An effective route based on space-confined chemical reaction to synthesize uniform $\mathrm{Li}_{2} \mathrm{Mg}(\mathrm{NH})_{2}$ nanoparticles is reported. The hierarchical pores inside the onedimensional carbon nanofibers (CNFs), induced by the creation of well-dispersed $\mathrm{Li}_{3} \mathrm{~N}$, serve as intelligent nanoreactors for the reaction of $\mathrm{Li}_{3} \mathrm{~N}$ with $\mathrm{Mg}$-containing precursors, resulting in the formation of uniformly discrete $\mathrm{Li}_{2} \mathrm{Mg}(\mathrm{NH})_{2}$ nanoparticles. The nanostructured $\mathrm{Li}_{2} \mathrm{Mg}(\mathrm{NH})_{2}$ particles inside the CNFs is capable of complete hydrogenation and dehydrogenation at a temperature as low as $105{ }^{\circ} \mathrm{C}$ with the suppression of ammonia release. Furthermore, by virtue of the nanosize effects and space-confinement by the porous carbon scaffold, no degradation was observed after 50 de-/re-hydrogenation cycles at a temperature as low as $130{ }^{\circ} \mathrm{C}$ for the asprepared $\mathrm{Li}_{2} \mathrm{Mg}(\mathrm{NH})_{2}$ nanoparticles, indicating excellent reversibility. Moreover, the theoretical calculations demonstrate that the reduction in particle size could significantly enhance the $\mathrm{H}_{2}$ sorption of $\mathrm{Li}_{2} \mathrm{Mg}(\mathrm{NH})_{2}$ by decreasing the relative activation energy barrier, which agrees well with our experimental results. This method could represent an effective, general strategy for synthesizing nanoparticles of complex hydrides with stable reversibility and excellent hydrogen storage performance. 


\section{INTRODUCTION}

As a renewable fuel, hydrogen has been widely acknowledged as the ideal synthetic fuel for onboard application because of its abundance, high chemical energy, and environmental friendliness (with water as the sole product from combustion). ${ }^{1,2}$ The storage of $\mathrm{H}_{2}$ in a safe, efficient, and economical manner, however, remains a big challenge to the realization of the socalled hydrogen economy. ${ }^{3-5}$ Metal-N-H systems have been considered among the most promising materials, after $\mathrm{Li}_{3} \mathrm{~N}$ was shown to reversibly store $\sim 11.4$ wt. $\% \mathrm{H}_{2}$ via the following two-step reaction (1). Related systems have received growing attention due to their relatively high reversible hydrogen capacity. ${ }^{6,7}$

$$
\mathrm{Li}_{3} \mathrm{~N}+2 \mathrm{H}_{2} \leftrightarrow \mathrm{Li}_{2} \mathrm{NH}+\mathrm{LiH}+\mathrm{H}_{2} \leftrightarrow \mathrm{LiNH}_{2}+2 \mathrm{LiH}
$$

The rather high dehydrogenation enthalpy for the leftmost reaction, $\sim 115 \mathrm{~kJ} \mathrm{~mol}^{-1} \mathrm{H}_{2}$, places thermodynamic constraints on this system, such that the complete generation of $\mathrm{Li}_{3} \mathrm{~N}$ can be achieved only at temperatures above $320{ }^{\circ} \mathrm{C}$, even under dynamic vacuum. ${ }^{8}$ Given the favorable enthalpy value $\left(-45 \mathrm{~kJ} \mathrm{~mol}^{-1}\right)$, only the second reaction step is considered to be practical for hydrogen storage, which significantly degrades the practical $\mathrm{H}_{2}$ storage capacity to $\sim 6.5 \mathrm{wt} . \%$, based on pure $\mathrm{Li}_{2} \mathrm{NH} .{ }^{9}$ Furthermore, numerous experimental and theoretical results have verified that simple chemical modification of the Li-N-H system by Mg creates the novel Li-Mg-N-H system (Equation 2), whose dehydrogenation enthalpy is significantly reduced to approximately $39 \mathrm{~kJ} \mathrm{~mol}^{-1} \mathrm{H}_{2}$, which corresponds to an operating temperature of $90{ }^{\circ} \mathrm{C}$ at 1 bar of equilibrium hydrogen pressure. ${ }^{10-13}$ These parameters satisfy the practical requirements for operation in proton exchange membrane fuel cells (PEMFCs). ${ }^{14,15}$

$$
\mathrm{Mg}\left(\mathrm{NH}_{2}\right)_{2}+2 \mathrm{LiH} \leftrightarrow \mathrm{Li}_{2} \mathrm{Mg}(\mathrm{NH})_{2}+2 \mathrm{H}_{2}
$$


Nonetheless, it must be pointed out that both the dehydrogenation and the hydrogenation of any metal-N-H composites involve the interaction of multiple solid-state intermediate phases, including amides, imides, and hydrides. ${ }^{16,17}$ The sluggish interface reactions, resulting from the relocation of atoms (such as $\mathrm{Li}^{+}, \mathrm{Mg}^{2+}$, and $\mathrm{H}^{+}$ions) across amide-imide and imide-hydride phase boundaries and the mass transport along the thus-formed imide layer during the $\mathrm{H}_{2}$ ab-/desorption for the metal-N-H system, normally exhibit rather high activation energy barriers. These constraints tremendously raise the operating temperatures required for hydrogen storage and therefore preclude its practical applications. ${ }^{14,} 18,19$ In particular, the activation energy for the dehydrogenation of $\mathrm{Mg}\left(\mathrm{NH}_{2}\right)_{2} / 2 \mathrm{LiH}$ composite is up to $\sim 102-120 \mathrm{~kJ} \mathrm{~mol}^{-1}$, which renders it a reasonable kinetics only at temperatures above $200{ }^{\circ} \mathrm{C} \cdot{ }^{20-22}$ It should be noted that, in order to realize the practical applications of hydrogen storage materials, the thermodynamics and kinetics of storage reaction, which are the key parameters to determine the reversible storage performance of materials, should be dual-tuned. ${ }^{23-25}$ One effective strategy for dual-tuning the thermodynamics and kinetics of the metal-N-H system is to reduce the particle sizes down to the nanometer range, which would effectively improve the hydrogen storage performance due to the shortened diffusion distances between amides/imides and hydrides, and the increased surface area. ${ }^{6,26-29}$ A strong dependence of the de-/re-hydrogenation kinetics (and thermodynamics) on particle size has been demonstrated both experimentally and theoretically. ${ }^{30-41}$ For instance, the $\mathrm{Li}_{3} \mathrm{~N}$ obtained from the decomposition of precursors that are space-confined in mesoporous carbonaceous hosts shows much faster absorption and desorption kinetics than its bulk counterpart, so that the hydrogen storage process of the nanoconfined $\mathrm{Li}_{3} \mathrm{~N}$ was found to be fully reversible at $200{ }^{\circ} \mathrm{C} .{ }^{42,} 43$ Unfortunately, due to its multiphase constitution with high chemical activity, low solubility, and/or high melting point, the nanoengineering of Li-Mg-N-H composite 
has, to date, been limited to the technique of ball milling. ${ }^{13}$ Although, compared to the handmilled composite, a dramatic $61 \%$ reduction of activation energy and the onset temperature of $~$ $80{ }^{\circ} \mathrm{C}$ for hydrogenation can be realized for the nanosized $\mathrm{Li}_{2} \mathrm{Mg}(\mathrm{NH})_{2}$ by long ball milling. Unfortunately, the particles with small sizes are apt to grow and aggregate to minimize their surface energy during long-term cyclic heat treatment for $\mathrm{H}_{2}$ release and uptake. ${ }^{28,} 34$ This inevitable particle growth and phase separation result in heavy degradation of the sorption kinetics and cycling capacity. Additionally, it is well-known that it is difficult to control the particle size and particle agglomeration with mechanical milling, while cold welding during the milling process limits the decrease in particle size to a minimum of $1 \mu \mathrm{m} .{ }^{29,44}$ Therefore, it is still a significant challenge and of key importance to develop effective strategies for the synthesis of high-temperature-stable nanoparticles of $\mathrm{Li}_{2} \mathrm{Mg}(\mathrm{NH})_{2}$ with high hydrogen cycling stability.

Recently, we successfully synthesized carbon-coated $\mathrm{Li}_{3} \mathrm{~N}$ nanoparticles inside carbon nanofibers (CNFs) via a simple electrospinning technique with low-cost. ${ }^{43}$ Remarkably enhanced kinetics and thermodynamics were achieved due to the significant reduction in particle size and the even distribution of as-prepared $\mathrm{Li}_{3} \mathrm{~N}$ nanoparticles. The cycling temperature, however, was still higher than $200{ }^{\circ} \mathrm{C}$, resulting from thermodynamic limitations. Fortunately, the special yolkshell-type $\mathrm{Li}_{3} \mathrm{~N} @ \mathrm{C}$ nanostructure inside the hierarchical porous CNFs renders it a potential intelligent nanoreactor to fabricate a new system via further chemical modification. Herein, a novel approach to the synthesis of uniformly discrete $\mathrm{Li}_{2} \mathrm{Mg}(\mathrm{NH})_{2}$ nanoparticles with high purity through confined nanospace synthesis (CNS) is reported, as schematically illustrated in Figure 1. The chemical transformation of $\mathrm{Li}_{3} \mathrm{~N}$ into $\mathrm{Li}_{2} \mathrm{Mg}(\mathrm{NH})_{2}$ within the nanoscale range is realized via the introduction of magnesium precursors by solution infiltration into the void spaces of every discrete carbon-encapsulated $\mathrm{Li}_{3} \mathrm{~N}$ nanostructure, which is then annealed under ammonia and 
vacuum within the confined nanospace. The carbon framework physically separates the individual $\mathrm{Li}_{2} \mathrm{Mg}(\mathrm{NH})_{2}$ nanoparticles, allowing them to keep their original shape, size, and surface state, and thus tremendously improves their stability at the high temperatures required for hydrogenation and dehydrogenation. Remarkably, the physical space-confinement effects and nanostructural features that are provided by the $\mathrm{Li}_{2} \mathrm{Mg}(\mathrm{NH})_{2} @ \mathrm{C}$ nanostructure induce lowtemperature reversible hydrogenation and dehydrogenation; fast sorption kinetics; and long-term cycling stability.

\section{RESULTS AND DISCUSSION}

Panoramic field-emission scanning electron microscope (FESEM) and transmission electron microscope (TEM) images show that the spinning process produces a highly uniform nonwoven mat of polyvinyl alcohol (PVA) nanofibers (NFs) containing $\mathrm{LiN}_{3}$ (Figure $\mathrm{S} 1$ in the Supporting Information), and the fibrous architecture was well maintained after calcination of the aselectrospun NFs (Figure 2a). Additionally, during heat treatment, the explosive decomposition of $\mathrm{LiN}_{3}$ inside the PVA NFs could effectively push the surrounding flexible PVA aside, leaving behind visible void space around the as-formed $\mathrm{Li}_{3} \mathrm{~N}$ nanoparticles. After carbonization of the PVA into sturdy carbon, the thus-formed Li $3 \mathrm{~N} @ \mathrm{C}$ NFs consist of a carbon framework that surrounds uniform spherical voids with embedded $\mathrm{Li}_{3} \mathrm{~N}$ nanoparticles. This results in mesopores and macropores with various diameters on the surfaces along the length of the NFs (Figure $2 b$ ) and inside the fibers as shown in the cross-sectional images (Figure 2c), in which carbonencapsulated $\mathrm{Li}_{3} \mathrm{~N}$ nanoparticles are enclosed inside the CNFs. TEM studies provide further insight into the porous interior and detailed structure of the as-synthesized CNFs. In agreement with the FESEM observations, the even dispersion of mesopores and micropores is clearly confirmed (Figure 3a, b). Based on the Brunauer-Emmett-Teller (BET) analysis, $\mathrm{N}_{2}$ adsorption- 
desorption isotherms (Figure $\mathrm{S} 2$ ) of the obtained CNFs with $\mathrm{Li}_{3} \mathrm{~N}$ nanoparticles exhibit representative type IV curves with a sharp increase in the nitrogen absorption at a high relative pressure, which is indicative of a pore-size distribution in the mesoporous and macroporous ranges, with a pore volume of $0.681 \mathrm{~cm}^{3} \mathrm{~g}^{-1}$. It is worth noting that the good dispersion of holes inside the CNFs indirectly confirms the homogeneous distribution of $\mathrm{Li}_{3} \mathrm{~N}$, which was further verified by the homogeneous distribution of both carbon and nitrogen atoms (Figure S3) in the elemental mapping. The holes provide sufficient room for accommodating the infiltration of subsequent precursors, i.e., Mg-containing species, inside the porous carbon-encapsulated $\mathrm{Li}_{3} \mathrm{~N}$ nanostructure. The interfiber pores, a signature feature of fibrous membranes derived from electrospinning, provide abundant macroporous channels for the convenient transportation of liquid-phase-containing precursors to uniformly diffuse into each individual CNF. ${ }^{45}$ The extensive presence of micropores and/or mesopores across the whole CNF is attributed to the free volume and microporosity derived from the disordered packing of turbostratic carbon sheets and clusters during carbonization of the polymeric framework. A BET surface area of $72 \mathrm{~cm}^{2} \mathrm{~g}^{-1}$ was determined for the micropores by the t-plot method. This offers a sufficient driving force for the diffusion of the liquid precursors via capillary effects into the pores containing $\operatorname{Li}_{3} \mathrm{~N}$. Therefore, the one-dimensional hierarchical porous morphology of the as-obtained CNFs provides special spatial advantages for the fine-tuning of a homogeneous distribution of the precursors.

After infiltration of a solution of dibutylmagnesium $\left(\mathrm{MgBu}_{2}\right)$ by the capillary effect into the porous carbon-encapsulated $\mathrm{Li}_{3} \mathrm{~N}$ structure, removal of the solvent, and hydrogenation, the $\mathrm{Li}_{3} \mathrm{~N}$ particles can be transformed into a mixture of $\mathrm{LiNH}_{2}$ and $\mathrm{LiH}$ that are in-situ coated by the resulting $\mathrm{MgH}_{2}$. The particles are completely hydrided via Equations (3) and (4), and then 
annealed under ammonia to form a nanostructured composite of $\mathrm{Mg}\left(\mathrm{NH}_{2}\right)_{2}-2 \mathrm{LiNH}_{2}$ (Equations (5) and (6)).

$$
\begin{aligned}
& \mathrm{Li}_{3} \mathrm{~N}+2 \mathrm{H}_{2} \rightarrow \mathrm{LiNH}_{2}+2 \mathrm{LiH} \\
& \mathrm{Mg}\left(\mathrm{C}_{4} \mathrm{H}_{9}\right)_{2}+\mathrm{H}_{2} \rightarrow \mathrm{MgH}_{2}+2 \mathrm{C}_{4} \mathrm{H}_{10} \\
& \mathrm{LiH}+\mathrm{NH}_{3} \rightarrow \mathrm{LiNH}_{2}+\mathrm{H}_{2} \\
& \mathrm{MgH}_{2}+2 \mathrm{NH}_{3} \rightarrow \mathrm{Mg}\left(\mathrm{NH}_{2}\right)_{2}+2 \mathrm{H}_{2} \\
& \mathrm{Mg}\left(\mathrm{NH}_{2}\right)_{2}+2 \mathrm{LiNH}_{2} \rightarrow \mathrm{Li}_{2} \mathrm{Mg}(\mathrm{NH})_{2}+2 \mathrm{NH}_{3}
\end{aligned}
$$

Due to the physical confinement by the surrounding carbon framework, further calcination under vacuum leads to the formation of $\mathrm{Li}_{2} \mathrm{Mg}(\mathrm{NH})_{2}$ on the nanometer scale, accompanied by the release of ammonia according to Equation (7). ${ }^{13}$ The structural morphology of the CNFs is well maintained without apparent deformation after the thermolysis reaction, which results in the formation of $\operatorname{Li}_{2} \mathrm{Mg}(\mathrm{NH})_{2}$. The porous structure is mostly preserved (Figure 3c), indicating the formation of the porous carbon-encapsulated $\operatorname{Li}_{2} \mathrm{Mg}(\mathrm{NH})_{2}$ nanostructures inside the CNFs as well. This network provides a favorable channel for hydrogen loading and unloading of the confined $\mathrm{Li}_{2} \mathrm{Mg}(\mathrm{NH})_{2}$ nanoparticles.

The chemical transformation from $\mathrm{Li}_{3} \mathrm{~N}$ via the diffusion of Mg-containing precursors to $\mathrm{Li}_{2} \mathrm{Mg}(\mathrm{NH})_{2}$ inside the $\mathrm{CNFs}$ is clearly confirmed by the combination of powder X-ray diffraction (PXRD) (Figure S4) and Fourier transform infrared (FTIR) spectra (Figure S5). The phase composition after calcination of the as-electrospun NFs can be unambiguously assigned to $\mathrm{Li}_{3} \mathrm{~N}$. After hydrogenation, the appearance of peaks belonging to $\mathrm{MgH}_{2}$ is accompanied by the 
disappearance of $\mathrm{Li}_{3} \mathrm{~N}$. The appearance of the characteristic peaks of $\mathrm{LiNH}_{2}$ in the FTIR spectra suggests the successful generation of $\mathrm{LiNH}_{2}$ and $\mathrm{LiH}$. Nonetheless, no Bragg peaks of $\mathrm{LiH}$ and $\mathrm{LiNH}_{2}$ are visible in the PXRD patterns, indicating the formation of an amorphous and/or nanocrystalline structure due to the physical confinement by the CNFs. After ammoniation, absorbances readily assigned to both $\mathrm{LiNH}_{2}$ and $\mathrm{Mg}\left(\mathrm{NH}_{2}\right)_{2}$ are observed, and further heating under vacuum leads to the formation of pure cubic $\beta-\mathrm{Li}_{2} \mathrm{Mg}(\mathrm{NH})_{2}$ phase, as evidenced by the PXRD (Figure S4) and FTIR (Figure S5) spectra. These results indicate the complete conversion of the precursors to crystalline high purity products. Using the Scherrer formula, the average crystallite sizes of the $\operatorname{Li}_{2} \mathrm{Mg}(\mathrm{NH})_{2}$ particles were calculated to be approximately $4.2 \mathrm{~nm}$. The nanosize nature of the particles can be attributed to the good dispersion and the effective steric hindrance effects of the carbon shells during the synthetic process. In addition, the $\mathrm{C}$ map in the electron energy loss spectrum (EELS) (Figure 3d) agrees well with the fibrous structure of the CNFs, and the $\mathrm{Li}, \mathrm{Mg}$, and $\mathrm{N}$ elemental maps correspond well with the $\mathrm{C}$ map from EELS, directly confirming the good dispersion of $\mathrm{Li}_{2} \mathrm{Mg}(\mathrm{NH})_{2}$ nanoparticles inside the CNFs.

Figure 4a shows the mass spectroscopy (MS) results for the as-prepared $\mathrm{Li}_{2} \mathrm{Mg}(\mathrm{NH})_{2} @ \mathrm{C} \mathrm{NFs}$ in comparison with the $\mathrm{Li}_{3} \mathrm{~N} @ \mathrm{C}$ NFs and the ball-milled $\mathrm{Li}_{2} \mathrm{Mg}(\mathrm{NH})_{2}$ composite after full hydrogenation. It is demonstrated that the nanoscale $\mathrm{Li}_{3} \mathrm{~N}$ entrapped in the CNFs starts to release hydrogen at $\sim 120{ }^{\circ} \mathrm{C}$, with a peak temperature as high as $\sim 250{ }^{\circ} \mathrm{C}$. Upon the introduction of $\mathrm{Mg}$ into the $\mathrm{Li}-\mathrm{N}-\mathrm{H}$ system, the resulting $\mathrm{Mg}\left(\mathrm{NH}_{2}\right)_{2}-2 \mathrm{LiH}$ composite exhibits a peak temperature of $\sim 198^{\circ} \mathrm{C}$ after only a slight ball milling. This confirms the importance of Mg substitution for the improvement of the hydrogen storage properties of $\mathrm{Li}-\mathrm{N}-\mathrm{H}$ composite. It should be noted, however, that a simultaneous release of ammonia was detected for the ball-milled $\mathrm{Mg}\left(\mathrm{NH}_{2}\right)_{2}-$ $2 \mathrm{LiH}$ composite, which can be attributed to the incomplete reaction of the components. ${ }^{27} \mathrm{By}$ 
contrast, chemical modification of the $\mathrm{Li}_{3} \mathrm{~N} @ \mathrm{C}$ NFs by reaction with $\mathrm{Mg}$ through the CNS route in the porous $\mathrm{CNFs}$ gives rise to the synthesis of $\mathrm{Li}_{2} \mathrm{Mg}(\mathrm{NH})_{2}$ nanoparticles, which, after hydrogenation, exhibit an onset temperature of $\sim 80^{\circ} \mathrm{C}$ with a peak temperature of $\sim 118{ }^{\circ} \mathrm{C}$. This is $80{ }^{\circ} \mathrm{C}$ and $132{ }^{\circ} \mathrm{C}$ lower than for the ball-milled counterpart and the as-prepared $\mathrm{Li}_{3} \mathrm{~N} @ \mathrm{C} \mathrm{NFs}$, respectively. More importantly, the release of detectable ammonia during the thermal dehydrogenation process is tremendously hindered, possibly due to the intimate contact between $\mathrm{Mg}\left(\mathrm{NH}_{2}\right)_{2}$ and $\mathrm{LiH}$ induced by the nanosize effects. The desorption of high purity hydrogen was confirmed by the thermogravimetric (TG) method (Figure S6), which gives a weight loss of $\sim 5.5$ wt.\% (2.1 wt.\% in overall composite mass), corresponding well with its theoretical value (5.6 wt.\%) based on Equation (2). Moreover, volumetric temperature-programmed desorption (TPD) results (Figure S7) verify a storage capacity of $\sim 0.0105 \mathrm{~mol} \mathrm{~g}^{-1}$ released from $\mathrm{Li}_{2} \mathrm{Mg}(\mathrm{NH})_{2} @ \mathrm{C}$ NFs after complete hydrogenation, corresponding to a weight loss of $2.1 \mathrm{wt} . \%$ from overall composite mass, which therefore further confirms the high-purity of the released hydrogen. The transformation between $\mathrm{Li}_{2} \mathrm{Mg}(\mathrm{NH})_{2}$ and $\mathrm{Mg}\left(\mathrm{NH}_{2}\right)_{2} / \mathrm{LiH}$ composite accounting for the hydrogen storage reaction of $\mathrm{Li}_{2} \mathrm{Mg}(\mathrm{NH})_{2} @ \mathrm{C} \mathrm{NFs}$ could be further demonstrated by PXRD results (Figure S8), which provides direct evidence for the formation of $\mathrm{Mg}\left(\mathrm{NH}_{2}\right)_{2} / \mathrm{LiH}$ composite after hydrogenation and the synthesis of $\mathrm{Li}_{2} \mathrm{Mg}(\mathrm{NH})_{2}$ after dehydrogenation.

Thermodynamic stabilities and the reversibility at various temperatures were determined from pressure-composition-isotherm (PCI) measurements that were carried out on the nanosized and ball-milled $\mathrm{Li}_{2} \mathrm{Mg}(\mathrm{NH})_{2}$ (Figures $4 \mathrm{~b}$ and $\mathrm{S} 9$ ). It can be observed that, the plateau pressures for the nanoscale $\mathrm{Li}_{2} \mathrm{Mg}(\mathrm{NH})_{2}$ show a well-defined plateau region at each temperature and, at a temperature as low as $105{ }^{\circ} \mathrm{C}$, a complete cycle of $\mathrm{H}_{2}$ absorption and desorption with a capacity of $\sim 5.5$ wt. $\%$ ( $\sim 2.1$ wt. $\%$ per mass of the overall composite) could be achieved, approaching its 
theoretical value from Equation (2). The capacities for both hydrogenation and dehydrogenation for the ball-milled $\operatorname{Li}_{2} \mathrm{Mg}(\mathrm{NH})_{2}$ are much less than $1 \mathrm{wt} . \%$, even at the high temperature of 130 ${ }^{\circ} \mathrm{C}$. Apparently, the plateau pressure increases with increasing temperature. The values for the enthalpy $\left(\Delta \mathrm{H}_{\text {des }}\right)$ and entropy $\left(\Delta \mathrm{S}_{\text {des }}\right)$ in dehydrogenation for the nanosized $\operatorname{Li}_{2} \mathrm{Mg}(\mathrm{NH})_{2}$ derived from the van't Hoff equation (Figure S10) were $35.7 \pm 0.5 \mathrm{~kJ} \mathrm{~mol}^{-1} \mathrm{H}_{2}$ and $100.2 \pm 1.3 \mathrm{~J} \mathrm{~K}^{-1} \mathrm{~mol}^{-}$ ${ }^{1} \mathrm{H}_{2}$, respectively, which are slightly lower than those of the bulk counterpart $\left(44.1 \mathrm{~kJ} \mathrm{~mol}^{-1} \mathrm{H}_{2}\right.$ and $\left.112 \mathrm{~J} \mathrm{~K}^{-1} \mathrm{~mol}^{-1} \mathrm{H}_{2}\right)^{14}$, indicating that thermodynamic destabilization occurs due to either reduction of the particle size down to the nanometer scale or the interaction of the confined $\mathrm{Li}_{2} \mathrm{Mg}(\mathrm{NH})_{2}$ with the carbon framework.

To gain further insight into the hydrogen storage properties of $\mathrm{Li}_{2} \mathrm{Mg}(\mathrm{NH})_{2}$ nanoparticles inside the CNFs, the $\mathrm{H}_{2}$ sorption in the isotherm models was investigated at different temperatures and in the $\mathrm{H}_{2}$-pressure range of 2.9-3.0 MPa for absorption and 0.001-0.01 MPa for desorption (Figures 5 and S11). At the temperature of $135^{\circ} \mathrm{C}$, a sharp weight increase upon exposure to hydrogen for the carbon-coated $\mathrm{Li}_{2} \mathrm{Mg}(\mathrm{NH})_{2}$ composite was observed during the first 20 min, which plateaus off to constant mass in less than 40 min with a capacity of $\sim 5.5 \mathrm{wt} . \%(2.1$ wt.\% in overall composite mass), and the following dehydrogenation confirmed that the charged $\mathrm{H}_{2}$ could be completely discharged when the dehydrogenation time was extended to $80 \mathrm{~min}$. The capacity of $\mathrm{H}_{2}$ uptake and release for the ball-milled $\mathrm{Li}_{2} \mathrm{Mg}(\mathrm{NH})_{2}$, however, is only $\sim 0.8$ wt. $\%$ and $\sim 0.7 \mathrm{wt} . \%$, respectively, at the same temperature. The significant improvement of both the dehydrogenation and the hydrogenation kinetics for the $\mathrm{Li}_{2} \mathrm{Mg}(\mathrm{NH})_{2} @ \mathrm{C}$ NFs was quantitatively determined by the apparent activation energies $\left(E_{\mathrm{a}}\right)$ during $\mathrm{H}_{2}$ release and uptake, as determined by the Arrhenius equation via fitting the experimental results at various temperatures. The apparent activation energies for hydrogenation and dehydrogenation of the porous 
$\mathrm{Li}_{2} \mathrm{Mg}(\mathrm{NH})_{2} @ \mathrm{C} \mathrm{NFs}$, from the slopes of the linear plots of $\ln (k)$ ( $k$, rate constant) versus $1 / T(T$, absolute temperature), were calculated to be $\sim 34.1$ and $37.2 \mathrm{~kJ} \mathrm{~mol}^{-1} \mathrm{H}_{2}$ (Figure S12), respectively, dramatically lower than for the bulk composite and other catalyst-added $\mathrm{Li}_{2} \mathrm{Mg}(\mathrm{NH})_{2}$ (Table S1). Therefore, these results provide direct evidence of the enhancement of the hydriding/dehydriding kinetics in the nanosized $\mathrm{Li}_{2} \mathrm{Mg}(\mathrm{NH})_{2}$ confined in the porous CNFs, owing to the decrease in the diffusion distances induced by the reduction of particle size.

The major obstacles to the practical application of the Li-Mg-N-H system in the bulk form are: sintering effects, phase separation, and the simultaneous release of ammonia upon heat treatment, which result in substantial degradation of hydrogen capacity during cycling. This is in contrast to the as-prepared $\mathrm{Li}_{2} \mathrm{Mg}(\mathrm{NH})_{2} @ \mathrm{C} \mathrm{NFs}$, which exhibit much lower de-/rehydrogenation temperatures and the depression of ammonia due to the reduction of particle size down to the nanometer scale. Moreover, the uniform porous carbon coating surrounding the $\mathrm{Li}_{2} \mathrm{Mg}(\mathrm{NH})_{2}$ nanoparticles as a continuous and flexible shell inside the CNFs serves as a nanoreactor and physically prevents particle growth and phase separation of the nanoparticles during the thermal reaction, while simultaneously accommodating the volume change that occurs during $\mathrm{H}_{2}$ uptake and release. This scaffold provides superior structural features for preserving the morphology of $\mathrm{Li}_{2} \mathrm{Mg}(\mathrm{NH})_{2}$ and enhancing its hydrogen storage performance. Therefore, the cycling stability of the as-prepared $\mathrm{Li}_{2} \mathrm{Mg}(\mathrm{NH})_{2} @ \mathrm{C} \mathrm{NFs}$, in comparison with their bulk counterpart, was further evaluated by isothermal hydrogenation and dehydrogenation at $130{ }^{\circ} \mathrm{C}$ using the volumetric method (Figure 6a). Notably, even with a dwell time of $400 \mathrm{~min}$ for one cycle at $130{ }^{\circ} \mathrm{C}$, the capacity retention of the bulk counterpart is already lower than $50 \%$ after 5 cycles of sorption. Nonetheless, there was only a minor loss in hydrogen capacity $(\sim 0.1 \mathrm{wt} . \%$ per mass of the overall composite) for the $\mathrm{Li}_{2} \mathrm{Mg}(\mathrm{NH})_{2} @ \mathrm{C} \mathrm{NFs}$, even after a total of 50 cycles 
(Figure 6b). More importantly, the kinetics and reversible hydrogen capacities of both dehydrogenation and hydrogenation remained intact from the first to the last cycle (Figure 6c). Also, ammonia is still undetectable during the $50^{\text {th }}$ desorption cycle (Figure S13), indicating the significantly improved robustness and cycling stability of $\mathrm{Li}_{2} \mathrm{Mg}(\mathrm{NH})_{2}$ on the nanometer scale, resulting from the space-confined synthesis inside the porous CNFs. It is well-known that the transformation of $\mathrm{Li}_{2} \mathrm{Mg}(\mathrm{NH})_{2}$ into $\mathrm{LiH}$ and $\mathrm{Mg}\left(\mathrm{NH}_{2}\right)_{2}$ according to Equation (2) necessitates the formation of $\mathrm{N}-\mathrm{H}$ bonds and the removal of $\mathrm{Li}$ atoms, thus indicating that not only lithiumrelated, but also hydrogen-related defects are required. The formation energies of the charged hydrogen interstitial $\left(\mathrm{I}_{\mathrm{H}}\right)$ and the lithium vacancy $\left(\mathrm{V}_{\mathrm{Li}}\right)$ for $\mathrm{Li}_{2} \mathrm{Mg}(\mathrm{NH})_{2}$ as a function of the Fermi energy $\left(\varepsilon_{\mathrm{F}}\right)$ are plotted in Figure $7 \mathrm{a}$. The lower limit for the Fermi level, $\varepsilon_{\mathrm{F}}=0 \mathrm{eV}$, corresponds to the top of the valence band (VBM), while the upper limit, $\varepsilon_{\mathrm{F}}=2.3 \mathrm{eV}$, represents the bottom of the conduction band (CBM). The vertical dotted line in Figure 7a denotes the position of the relevant value of the Fermi energy, which is found by determining the system with the lowest formation energy that is charge-neutral overall. Among the charged defects considered in this paper, the lowest formation energy is associated with $\mathrm{V}_{\mathrm{Li}}{ }^{-}$and $\mathrm{I}_{\mathrm{H}}{ }^{+}$, with formation energy of $-0.06 \mathrm{eV}$. Thus, in the absence of extrinsic impurities, charge neutrality must be achieved by equal concentrations of $\mathrm{V}_{\mathrm{Li}}{ }^{-}$and $\mathrm{I}_{\mathrm{H}}{ }^{+}$in the bulk, which pins the Fermi level at $\sim 2.01 \mathrm{eV}$. Compared to the bulk composite, however, samples composed of relatively small particles have a relatively larger surface-to-volume ratio, and therefore, the formation and diffusion of defects on their surfaces may prevail. Subsequently, we further calculated the formation of $\mathrm{V}_{\mathrm{Li}}{ }^{-}$and $\mathrm{IH}^{+}$pairs on the surface of $\mathrm{Li}_{2} \mathrm{Mg}(\mathrm{NH})_{2}$. The $\mathrm{Li}_{2} \mathrm{Mg}(\mathrm{NH})_{2}(100)$ surface has a substantially lower energy than the (010) and (001) surfaces, and therefore, we used this surface for the following calculations. Interestingly, our calculation results show that the 
formation energy of $\mathrm{V}_{\mathrm{Li}}{ }^{-}$and $\mathrm{IH}^{+}$pairs on the $\mathrm{Li}_{2} \mathrm{Mg}(\mathrm{NH})_{2}$ (100) surface is as low as $-1.61 \mathrm{eV}$. Hence, it can be expected that an increase in the surface-to-volume ratio would lead to a significant increase in the concentration of $\mathrm{V}_{\mathrm{Li}}{ }^{-}$and $\mathrm{I}_{\mathrm{H}}{ }^{+}$pairs on the surface.

Further investigation was focused on the migration process of the $\mathrm{H}$ and Li related defects, which involves mass transport and is related to the hydrogenation of $\operatorname{Li}_{2} \mathrm{Mg}(\mathrm{NH})_{2}$. The energy barriers for diffusion were estimated by using the climbing image - nudged elastic band (CINEB) method. Although numerous diffusion pathways in $\mathrm{Li}_{2} \mathrm{Mg}(\mathrm{NH})_{2}$ were examined, only the lowest energy paths observed are described herein. As shown in Figure $7 \mathrm{~b}$ and Figure S14, the diffusion barriers of $\mathrm{VLi}^{-}$and $\mathrm{I}_{\mathrm{H}}{ }^{+}$are 1.46 and $0.78 \mathrm{eV}$, respectively. The relatively low diffusion barrier for $\mathrm{IH}_{\mathrm{H}}^{+}$indicates that $\mathrm{IH}^{+}$could migrate at moderate temperature. The migration of $\mathrm{V}_{\mathrm{Li}}{ }^{-}$ with relatively higher energy barriers would limit the transport of $\mathrm{Li}$ in bulk $\mathrm{Li}_{2} \mathrm{Mg}(\mathrm{NH})_{2}$. By contrast, our calculations also indicate that the diffusion barrier for $\mathrm{V}_{\mathrm{Li}}{ }^{-}$on the surface is decreased to only $1.13 \mathrm{eV}, \sim 0.32 \mathrm{eV}$ lower than in the bulk matrix. These results suggest that increasing the surface-to-volume ratio by reducing particle size could significantly promote both the formation and the diffusion of $\mathrm{V}_{\mathrm{Li}}{ }^{-}$and $\mathrm{IH}^{+}$, thereby significantly improving the hydrogenation of $\mathrm{Li}_{2} \mathrm{Mg}(\mathrm{NH})_{2}$ to form $\mathrm{LiH}$ and $\mathrm{Mg}\left(\mathrm{NH}_{2}\right)_{2}$. The trend in our experimental activation energies agrees well with the computational results in terms of a bulk- versus surfacedominated mechanism for the hydrogenation of $\mathrm{Li}_{2} \mathrm{Mg}(\mathrm{NH})_{2}$. In the case of the ball-milled LiMg-N-H composite, the sizes of most of the particles are larger than $1 \mu \mathrm{m}$ (Figure S15), and therefore, the surface-to-volume ratio is small, which endows it with high activation energy. By contrast, it is notable that the fabrication of the porous carbon-encapsulated $\mathrm{Li}_{2} \mathrm{Mg}(\mathrm{NH})_{2}$ nanostructure via CNS can, on the one hand, realize the direct synthesis of nanosized 
$\mathrm{Li}_{2} \mathrm{Mg}(\mathrm{NH})_{2}(\sim 4.2 \mathrm{~nm})$ and its homogenous distribution, significantly improving its hydrogen storage performance (Figures 4 and 5), while, on the other hand, the additional geometric confinement effect of the porous carbon shells surrounding each $\mathrm{Li}_{2} \mathrm{Mg}(\mathrm{NH})_{2}$ nanoparticle can well preserve the nanostructural features down to the nanometer scale during consecutive cycles of heating, which therefore gives the $\mathrm{Li}_{2} \mathrm{Mg}(\mathrm{NH})_{2}$ stable reversibility without apparent degradation, even up to 50 cycles of de-/re-hydrogenation (Figure 6). Moreover, the 3D porous structure formed in situ also provides a favorable channel for the transportation of $\mathrm{H}_{2}$.

\section{CONCLUSION}

In summary, we report a facile, confined nanospace synthesis procedure for the preparation of high-performance, porous carbon-encapsulated $\mathrm{Li}_{2} \mathrm{Mg}(\mathrm{NH})_{2}$ nanostructures as hydrogen storage materials. The hierarchical porous CNFs that were synthesized through simple, low-cost electrospinning contain pores that arise during the formation of $\mathrm{Li}_{3} \mathrm{~N}$ that serve as intelligent nanoreactors. The carbon framework endows the as-prepared $\mathrm{Li}_{2} \mathrm{Mg}(\mathrm{NH})_{2}$ nanoparticles with a uniform distribution and effective space-confinement. The unique architecture of the $\mathrm{Li}_{2} \mathrm{Mg}(\mathrm{NH})_{2}$ nanoparticles allows complete cycles of hydrogenation and dehydrogenation at 105 ${ }^{\circ} \mathrm{C}$ with long-term cycling stability. Moreover, this strategy represents a highly novel approach to synthesizing nanostructured hydrogen storage materials that exhibit superior storage properties, including outstanding hydrogen cycling performances.

\section{ASSOCIATED CONTENT}

\section{Supporting Information.}

The following files are available free of charge. 
Additional text with experimental details; XRD, SEM images, FTIR, and TG results of the nanosized $\mathrm{Li}_{2} \mathrm{Mg}(\mathrm{NH})_{2}(\mathrm{PDF})$

\section{AUTHOR INFORMATION}

\section{Corresponding Author}

*Email: zguo@uow.edu.au (Z.G.).

*Email: yuxuebin@fudan.edu.cn (X.Y.).

\section{Author Contributions}

The manuscript was written through contributions of all authors. All authors have given approval to the final version of the manuscript.

\section{Notes}

The authors declare no competing financial interest.

\section{ACKNOWLEDGMENT}

This work was partially supported by the National Science Fund for Distinguished Young Scholars (51625102), the National Natural Science Foundation of China (51471053), the Science and Technology Commission of Shanghai Municipality (17XD1400700), and a Discovery Early Career Researcher Award (DE170100362). Part of this research was undertaken on the Powder Diffraction Beamline at the Australian Synchrotron, Victoria, Australia. The authors also would like to thank Dr. Tania Silver for critical reading of the manuscript.

\section{REFERENCES}


(1) Schlapbach, L.; Zuttel, A. Hydrogen-Storage Materials for Mobile Applications. Nature 2001, 414, 353-358

(2) Orimo, S.-i.; Nakamori, Y.; Eliseo, J. R.; Züttel, A.; Jensen, C. M. Complex Hydrides for Hydrogen Storage. Chem. Rev. 2007, 107, 4111-4132.

(3) Weidenthaler, C.; Felderhoff, M. Solid-State Hydrogen Storage for Mobile Applications: Quo Vadis? Energy Environ. Sci. 2011, 4, 2495-2502.

(4) Berseth, P. A.; Harter, A. G.; Zidan, R.; Blomqvist, A.; Araújo, C. M.; Scheicher, R. H.; Ahuja, R.; Jena, P. Carbon Nanomaterials as Catalysts for Hydrogen Uptake and Release in $\mathrm{NaAlH}_{4}$. Nano Lett. 2009, 9, 1501-1505.

(5) Grochala, W.; Edwards, P. P. Thermal Decomposition of the Non-Interstitial Hydrides for the Storage and Production of Hydrogen. Chem. Rev. 2004, 104, 1283-1316.

(6) Xie, L.; Zheng, J.; Liu, Y.; Li, Y.; Li, X. Synthesis of Li 2 NH Hollow Nanospheres with Superior Hydrogen Storage Kinetics by Plasma Metal Reaction. Chem. Mater. 2007, $20,282-286$.

(7) Chen, P.; Xiong, Z. T.; Luo, J. Z.; Lin, J. Y.; Tan, K. L. Interaction of Hydrogen with Metal Nitrides and Imides. Nature 2002, 420, 302-304.

(8) Chen, P.; Xiong, Z. T.; Luo, J. Z.; Lin, J. Y.; Tan, K. L. Interaction Between Lithium Amide and Lithium Hydride. J. Phys. Chem. B 2003, 107, 10967-10970.

(9) Ichikawa, T.; Hanada, N.; Isobe, S.; Leng, H.; Fujii, H. Mechanism of Novel Reaction from $\mathrm{LiNH}_{2}$ and $\mathrm{LiH}$ to $\mathrm{Li}_{2} \mathrm{NH}$ and $\mathrm{H}_{2}$ as a Promising Hydrogen Storage System. J. Phys. Chem. B 2004, 108, 7887-7892. 
(10) Leng, H.; Ichikawa, T.; Hino, S.; Nakagawa, T.; Fujii. H. Mechanism of Hydrogenation Reaction in the Li-Mg-N-H System. J. Phys. Chem. B 2005, 109, 10744-10748.

(11) Xiong, Z. T.; Wu, G. T.; Hu, H. J.; Chen, P. Ternary Imides for Hydrogen Storage. Adv. Mater. 2004, 16, 1522-1525.

(12) Leng, H.; Ichikawa, T.; Fujii, H. Hydrogen Storage Properties of $\mathrm{Li}-\mathrm{Mg}-\mathrm{N}-\mathrm{H}$ Systems with Different Ratios of $\mathrm{LiH} / \mathrm{Mg}\left(\mathrm{NH}_{2}\right)_{2}$. J. Phys. Chem. B 2006, 110, 1296412968.

(13) Liu, Y.; Zhong, K.; Luo, K.; Gao, M.; Pan, H.; Wang, Q. D. Size-Dependent Kinetic Enhancement in Hydrogen Absorption and Desorption of the $\mathrm{Li}-\mathrm{Mg}-\mathrm{N}-\mathrm{H}$ System. $J$. Am. Chem. Soc. 2009, 131, 1862-1870.

(14) Xiong, Z. T.; Hu, J. J.; Wu, G. T.; Chen, P.; Luo, W. F.; Gross, K.; Wang, J. Thermodynamic and Kinetic Investigations of the Hydrogen Storage in the Li-Mg-N-H System. J. Alloys Compd. 2005, 398, 235-239.

(15) Mauron, P.; Remhof, A.; Bliersbach, A.; Borgschulte, A.; Züttel, A.; Sheptyakov, D.; Gaboardi, M.; Choucair, M.; Pontiroli, D.; Aramini, M. Reversible Hydrogen Absorption in Sodium Intercalated Fullerenes. Int. J. Hydrogen Energy 2012, 37, 14307-14314.

(16) Akbarzadeh, A. R.; Ozoliņ̌s, V.; Wolverton, C. First-Principles Determination of Multicomponent Hydride Phase Diagrams: Application to the Li-Mg-N-H System. Adv. Mater. 2007, 19, 3233-3239.

(17) David, W. I. F.; Jones, M. O.; Gregory, D. H.; Jewell, C. M.; Johnson, S. R.; Walton, A.; Edwards, P. P. A Mechanism for Non-stoichiometry in the Lithium Amide/Lithium Imide Hydrogen Storage Reaction. J. Am. Chem. Soc. 2007, 129, 1594-1601. 
(18) Nayebossadri, S.; Aguey-Zinsou, K.-F. Destabilisation of the Li-N-H Hydrogen Storage System with Elemental Si. Phys. Chem. Chem. Phys. 2011, 13, 17683-17688.

(19) Lu, C.; Hu, J.; Kwak, J. H.; Yang, Z.; Ren, R.; Markmaitree, T.; Shaw, L. L. Study of the Effects of Mechanical Activation on $\mathrm{Li}-\mathrm{N}-\mathrm{H}$ Systems with ${ }^{1} \mathrm{H}$ and ${ }^{6} \mathrm{Li}$ Solid-State NMR. J. Power Sources 2007, 170, 419-424.

(20) Liu, Y.; Li, C.; Li, B.; Gao, M.; Pan, H. Metathesis Reaction-Induced Significant Improvement in Hydrogen Storage Properties of the KF-Added $\mathrm{Mg}\left(\mathrm{NH}_{2}\right)_{2}-2 \mathrm{LiH}$ System. J. Phys. Chem. C 2013, 117, 866-875.

(21) Pan, H.; Shi, S.; Liu, Y.; Li, B.; Yang, Y.; Gao, M. Improved Hydrogen Storage Kinetics of the Li-Mg-N-H System by Addition of $\mathrm{Mg}\left(\mathrm{BH}_{4}\right)_{2}$. Dalton Trans. 2013, 42, 3802-3811.

(22) Li, C.; Liu, Y.; Pang, Y.; Gu, Y.; Gao, M.; Pan, H. Compositional Effects on the Hydrogen Storage Properties of $\mathrm{Mg}\left(\mathrm{NH}_{2}\right)_{2}-2 \mathrm{LiH}-\mathrm{xKH}$ and the Activity of $\mathrm{KH}$ During Dehydrogenation Reactions. Dalton Trans. 2014, 43, 2369-2377.

(23) Ouyang, L. Z.; Cao, Z. J.; Wang, H.; Liu, J. W.; Sun, D. L.; Zhang, Q. A.; Zhu, M. Enhanced Dehydriding Thermodynamics and Kinetics in $\mathrm{Mg}(\mathrm{In})-\mathrm{MgF}_{2}$ Composite Directly Synthesized by Plasma Milling. J. Alloys Compd. 2014, 586, 113-117.

(24) Ouyang, L. Z.; Cao, Z. J.; Wang, H.; Liu, J. W.; Sun, D. L.; Zhang, Q. A.; Zhu, M. Dual-Tuning Effect of In on the Thermodynamic and Kinetic Properties of $\mathrm{Mg}_{2} \mathrm{Ni}$ Dehydrogenation. Int. J. Hydrogen Energy 2013, 38, 8881-8887.

(25) Cao, Z. J.; Ouyang, L. Z.; Wu, Y. Y.; Wang, H.; Liu, J. W.; Fang, F.; Sun, D. L.; Zhang, Q. A.; Zhu, M. Dual-Tuning Effects of In, Al, and Ti on the Thermodynamics and 
Kinetics of $\mathrm{Mg}_{85} \mathrm{In}_{5} \mathrm{Al}_{5} \mathrm{Ti}_{5}$ Alloy Synthesized by Plasma Milling. J. Alloys Compds. 2015, $623,354-358$.

(26) Osborn, W.; Markmaitree, T.; Shaw, L. L. The Long-Term Hydriding and Dehydriding Stability of the Nanoscale $\mathrm{LiNH}_{2}+\mathrm{LiH}$ Hydrogen Storage System. Nanotechnology 2009, 20, 204028.

(27) Xie, L.; Liu, Y.; Li, G.; Li, X. G. Improving Hydrogen Sorption Kinetics of the $\mathrm{Mg}\left(\mathrm{NH}_{2}\right)_{2}-\mathrm{LiH}$ System by Tuning Particle Size of the Amide. J. Phys. Chem. C 2009, $113,14523-14527$.

(28) Wang, J.; Hu, J.; Liu, Y.; Xiong, Z.; Wu, G.; Pan, H.; Chen, P. Effects of Triphenyl

Phosphate on the Hydrogen Storage Performance of the $\operatorname{Mg}\left(\mathrm{NH}_{2}\right)_{2}-2 \mathrm{LiH}$ System. $J$. Mater. Chem. 2009, 19, 2141-2146.

(29) Yang, J.; Li, D.; Fu, H.; Xin, G.; Zheng, J.; Li, X. In Situ Hybridization of $\mathrm{LiNH}_{2}-$ $\mathrm{LiH}-\mathrm{Mg}\left(\mathrm{BH}_{4}\right)_{2}$ Nano-Composites: Intermediate and Optimized Hydrogenation Properties. Phys. Chem. Chem. Phys. 2012, 14, 2857-2863.

(30) Ward, P. A.; Teprovich, J. A.; Peters, B.; Wheeler, J.; Compton, R. N.; Zidan, R. Reversible Hydrogen Storage in a $\mathrm{LiBH}_{4}-\mathrm{C}_{60}$ Nanocomposite. J. Phys. Chem. C 2013, $117,22569-22575$.

(31) Au, Y. S.; Obbink, M. K.; Srinivasan, S.; Magusin, P. C. M. M.; de Jong, K. P.; de Jongh, P. E. The Size Dependence of Hydrogen Mobility and Sorption Kinetics for Carbon-Supported $\mathrm{MgH}_{2}$ Particles. Adv. Funct. Mater. 2014, 24, 3604-3611.

(32) de Jongh, P. E.; Wagemans, R. W. P.; Eggenhuisen, T. M.; Dauvillier, B. S.; Radstake, P. B.; Meeldijk, J. D.; Geus, J. W.; de Jong, K. P. The Preparation of Carbon- 
Supported Magnesium Nanoparticles using Melt Infiltration. Chem. Mater. 2007, 19, 6052-6057.

(33) de Jongh, P. E.; Eggenhuisen, T. M. Melt Infiltration: An Emerging Technique for the Preparation of Novel Functional Nanostructured Materials. Adv. Mater. 2013, 25, $6672-6690$.

(34) de Jongh, P. E.; Allendorf, M.; Vajo, J. J.; Zlotea, C. Nanoconfined Light Metal Hydrides for Reversible Hydrogen Storage. MRS Bull. 2013, 38, 488-494.

(35) de Jongh, P. E.; Adelhelm, P. Nanosizing and Nanoconfinement: New Strategies Towards Meeting Hydrogen Storage Goals. ChemSusChem 2010, 3, 1332-1348.

(36) Nielsen, T. K.; Besenbacher, F.; Jensen, T. R. Nanoconfined Hydrides for Energy Storage. Nanoscale 2011, 3, 2086-2098.

(37) Nielsen, T. K.; Polanski, M.; Zasada, D.; Javadian, P.; Besenbacher, F.; Bystrzycki, J.; Skibsted, J.; Jensen, T. R. Improved Hydrogen Storage Kinetics of Nanoconfined $\mathrm{NaAlH}_{4}$ Catalyzed with $\mathrm{TiCl}_{3}$ Nanoparticles. ACS Nano 2011, 5, 4056-4064.

(38) Mueller, T.; Ceder, G. Effect of Particle Size on Hydrogen Release from Sodium Alanate Nanoparticles. ACS Nano 2010, 4, 5647-5656.

(39) Aguey-Zinsou, K.-F.; Ares-Fernández, J.-R. Synthesis of Colloidal Magnesium: A Near Room Temperature Store for Hydrogen. Chem. Mater. 2007, 20, 376-378.

(40) Christian, M.; Aguey-Zinsou, K.-F. Synthesis of Core-Shell NaBH $\mathrm{N}_{4} @ \mathrm{M}(\mathrm{M}=\mathrm{Co}$, $\mathrm{Cu}, \mathrm{Fe}, \mathrm{Ni}, \mathrm{Sn}$ ) Nanoparticles Leading to Various Morphologies and Hydrogen Storage Properties. Chem. Comm. 2013, 49, 6794-6796.

(41) Christian, M. L.; Aguey-Zinsou, K.-F. Core-Shell Strategy Leading to High Reversible Hydrogen Storage Capacity for $\mathrm{NaBH}_{4}$. ACS Nano 2012, 6, 7739-7751. 
(42) Demir-Cakan, R.; Tang, W. S.; Darwiche, A.; Janot, R. Modification of the Hydrogen Storage Properties of $\mathrm{Li}_{3} \mathrm{~N}$ by Confinement into Mesoporous Carbons. Energy Environ. Sci. 2011, 4, 3625-3631.

(43) Xia, G. L.; Li, D.; Chen, X.; Tan, Y.; Tang, Z.; Guo, Z. P.; Liu, H. K.; Liu, Z. W.; Yu, X. B. Carbon-Coated $\mathrm{Li}_{3} \mathrm{~N}$ Nanofibers for Advanced Hydrogen Storage. Adv. Mater. 2013, 25, 6238-6244.

(44) Wu, H. Strategies for the Improvement of the Hydrogen Storage Properties of Metal Hydride Materials. ChemPhysChem 2008, 9, 2157-2162.

(45) Li, D.; Xia, Y. Electrospinning of Nanofibers: Reinventing the Wheel? Adv. Mater. 2004, 16, 1151-1170. 


\section{FIGURES}

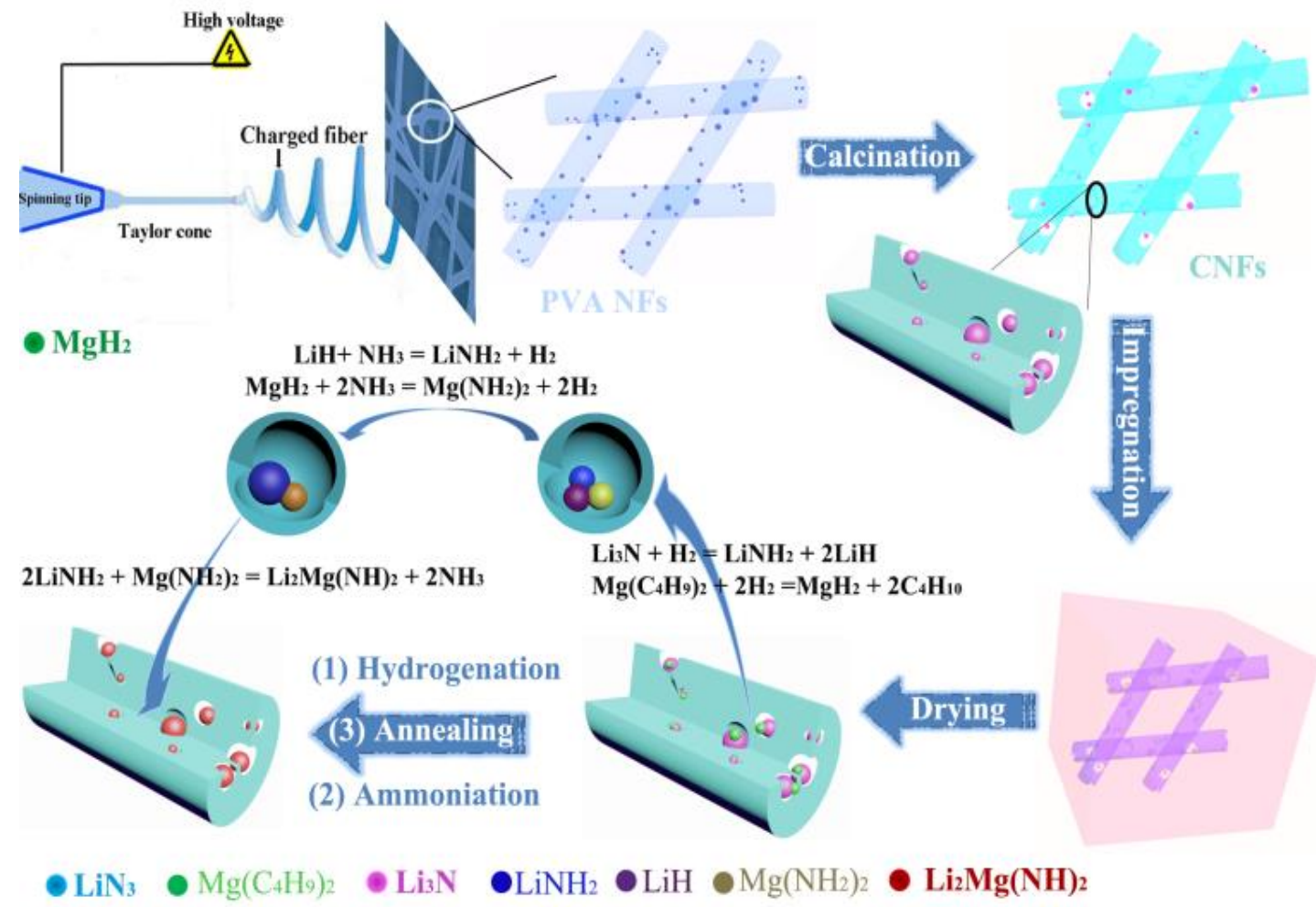

Figure 1. Schematic illustration of the preparation of $\mathrm{Li}_{2} \mathrm{Mg}(\mathrm{NH})_{2}$ nanoparticles inside the hierarchical porous CNFs from the as-electrospun PVA-coated $\mathrm{LiN}_{3} \mathrm{NFs}$. PVA is polyvinyl alcohol. 


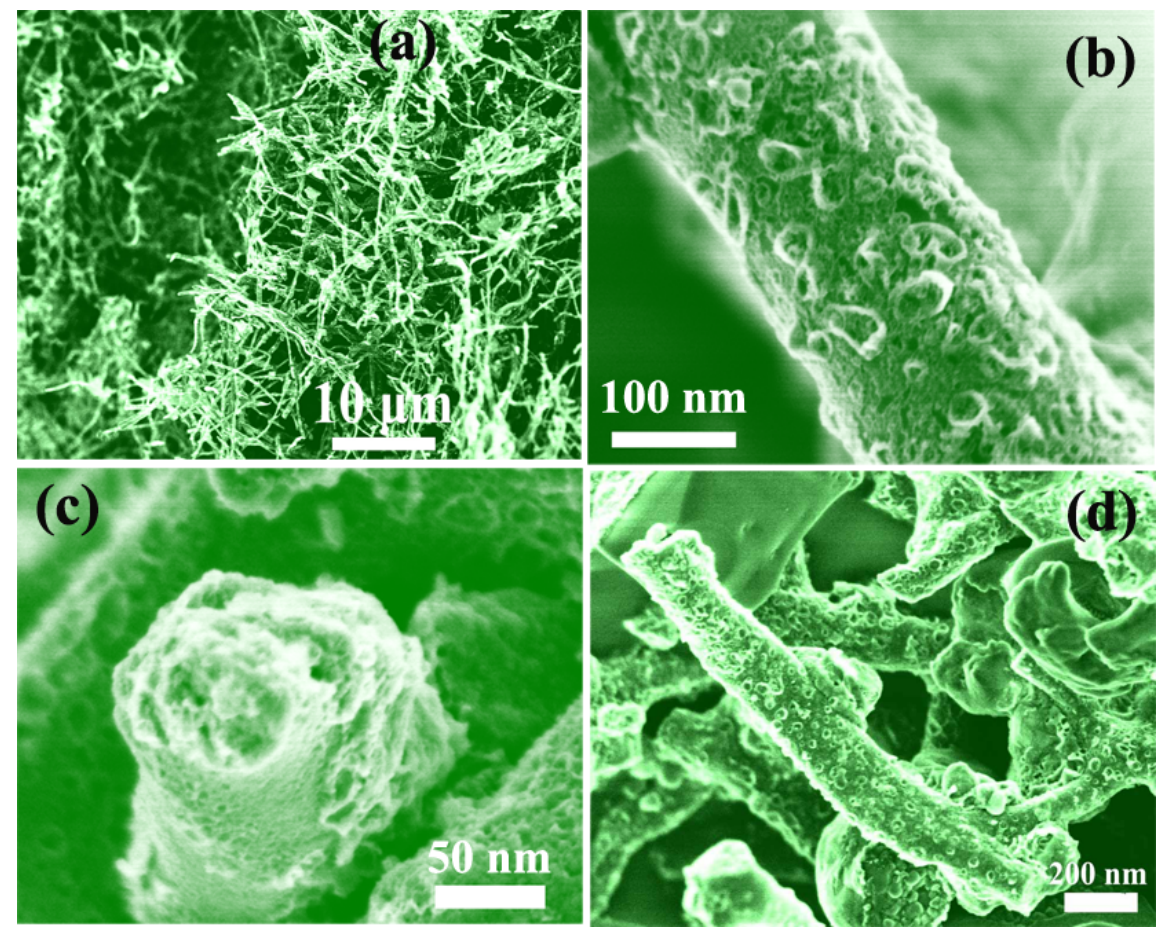

Figure 2. SEM images of the as-prepared (a, b, c) Li $3 \mathrm{~N} @ \mathrm{C}$ NFs and (d) Li $\mathrm{i}_{2} \mathrm{Mg}(\mathrm{NH})_{2} @ \mathrm{C} \mathrm{NFs}$. 


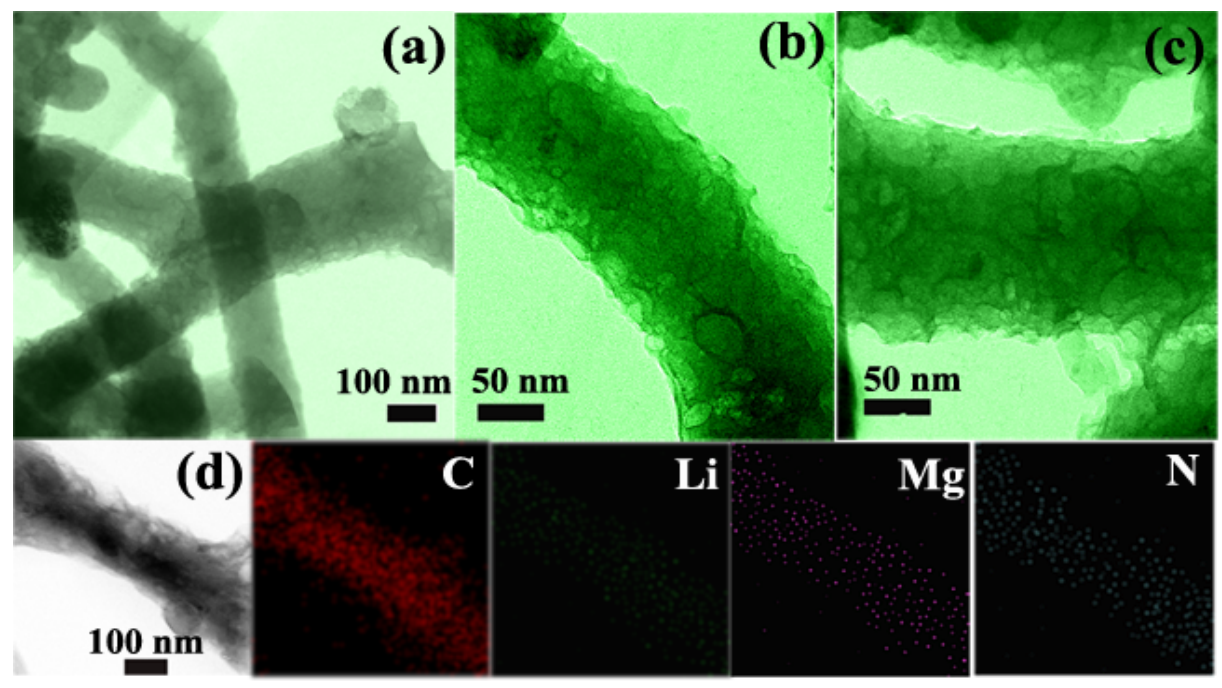

Figure 3. TEM images of (a, b) Li $i_{3} \mathrm{~N} @ \mathrm{C}$ NFs and (c) $\mathrm{Li}_{2} \mathrm{Mg}(\mathrm{NH})_{2} @ \mathrm{C}$ NFs. TEM image (d) and the corresponding elemental mapping of $\mathrm{Li}_{2} \mathrm{Mg}(\mathrm{NH})_{2} @ \mathrm{C}$ NFs. 


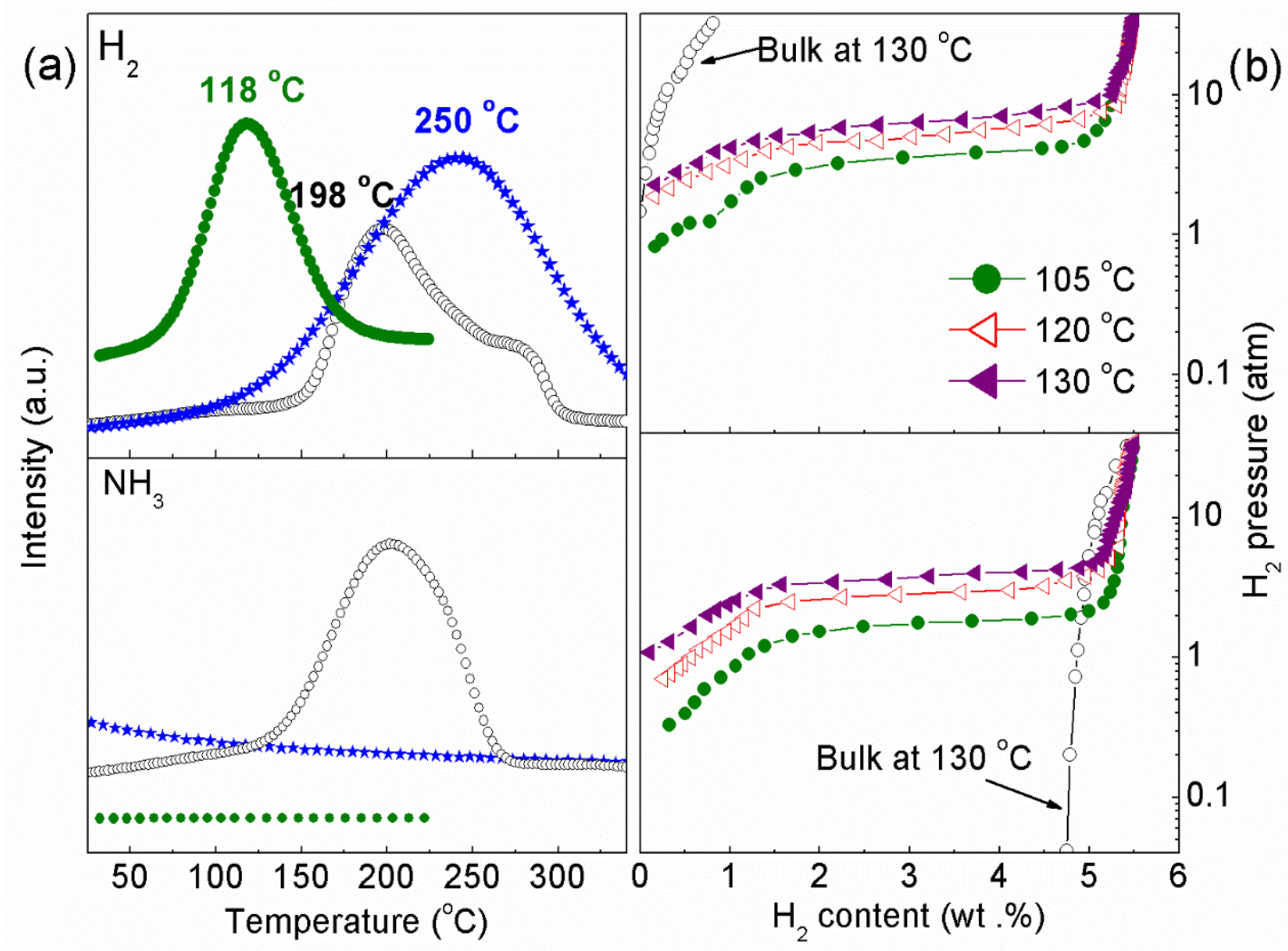

Figure 4. (a) Mass spectrum of the as-prepared $\mathrm{Li}_{2} \mathrm{Mg}(\mathrm{NH})_{2} @ \mathrm{C}$ NFs (green) after hydrogenation, in comparison with the $\mathrm{Li}_{3} \mathrm{~N} @ \mathrm{C}$ NFs (blue) and the ball-milled $\mathrm{Li}_{2} \mathrm{Mg}(\mathrm{NH})_{2}$ composite (black). (b) Pressure-composition isotherms (PCI) of the $\mathrm{Li}_{2} \mathrm{Mg}(\mathrm{NH})_{2} @ \mathrm{C}$ NFs at various temperatures, compared with the ball-milled $\mathrm{Li}_{2} \mathrm{Mg}(\mathrm{NH})_{2}$ composite at the temperature of $130{ }^{\circ} \mathrm{C}$. The $\mathrm{H}_{2}$ contents are expressed per mass of $\mathrm{Li}_{2} \mathrm{Mg}(\mathrm{NH})_{2}$. 


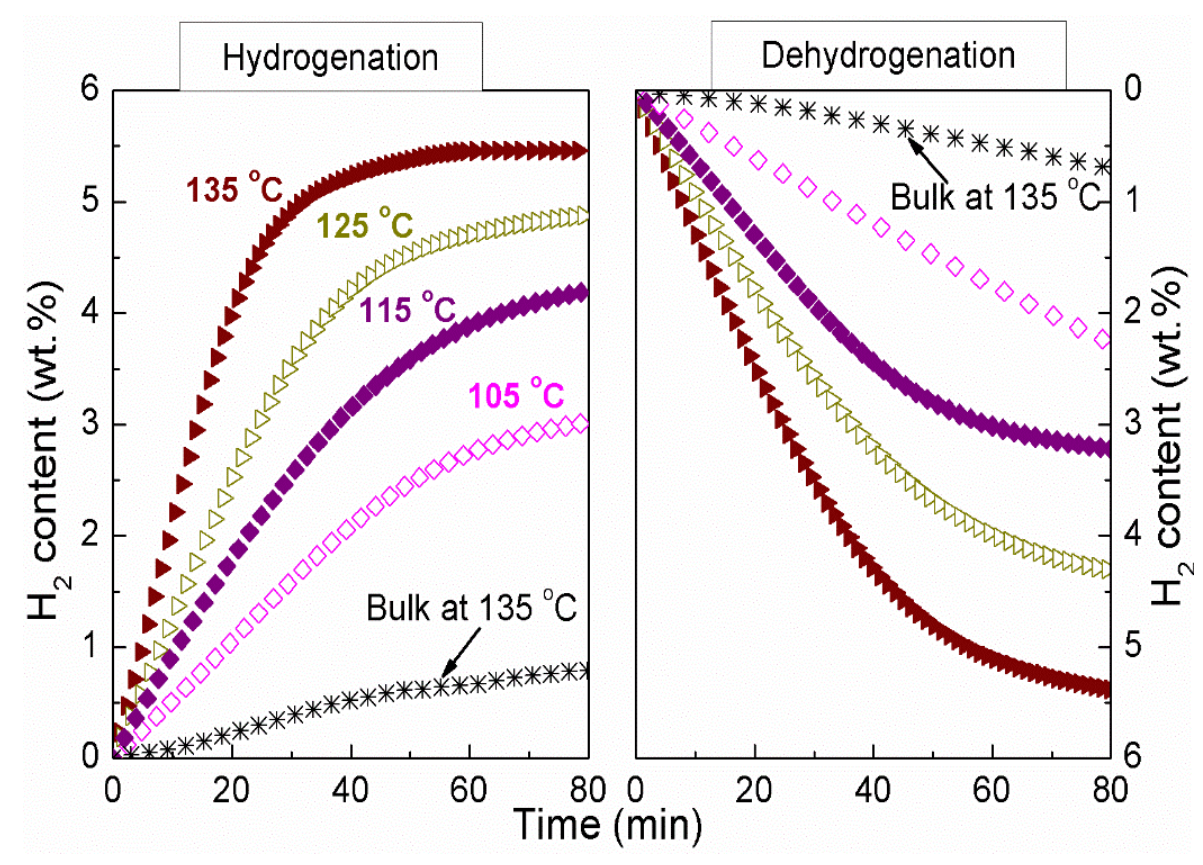

Figure 5. Hydrogenation and dehydrogenation of $\mathrm{Li}_{2} \mathrm{Mg}(\mathrm{NH})_{2} @ \mathrm{C}$ NFs at different temperatures, including the ball-milled $\mathrm{Li}_{2} \mathrm{Mg}(\mathrm{NH})_{2}$ at $130{ }^{\circ} \mathrm{C}$ for comparison. The $\mathrm{H}_{2}$ contents are expressed per mass of $\mathrm{Li}_{2} \mathrm{Mg}(\mathrm{NH})_{2}$. 

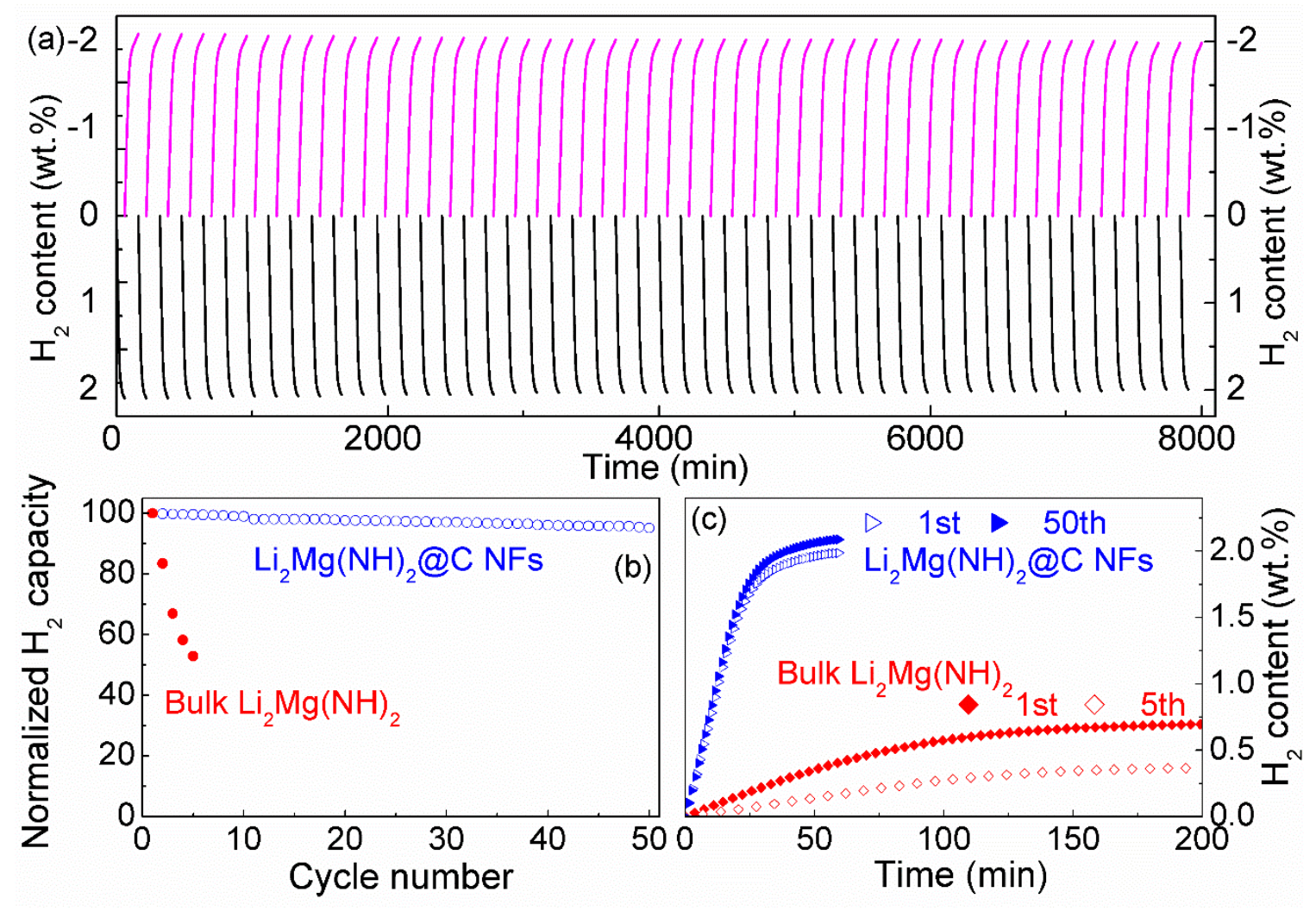

Figure 6. (a) Long-term cycling tests of hydrogenation (black lines) and dehydrogenation (pink lines) for $\mathrm{Li}_{2} \mathrm{Mg}(\mathrm{NH})_{2} @ \mathrm{C}$ NFs at $130{ }^{\circ} \mathrm{C}$; (b) normalized $\mathrm{H}_{2}$ capacity as a function of cycle number, where the hydrogen capacities are normalized to unity for the first value; and (c) comparison of the kinetics for hydrogenation/dehydrogenation of $\mathrm{Li}_{2} \mathrm{Mg}(\mathrm{NH})_{2} @ \mathrm{C}$ NFs between the $1^{\text {st }}$ and $50^{\text {th }}$ cycles at $130{ }^{\circ} \mathrm{C}$, including the $1^{\text {st }}$ and $5^{\text {th }}$ cycles of bulk $\mathrm{Li}_{2} \mathrm{Mg}(\mathrm{NH})_{2}$ for comparison. The $\mathrm{H}_{2}$ contents are expressed here per mass of the whole composite (i.e., including the weight of CNFs). 

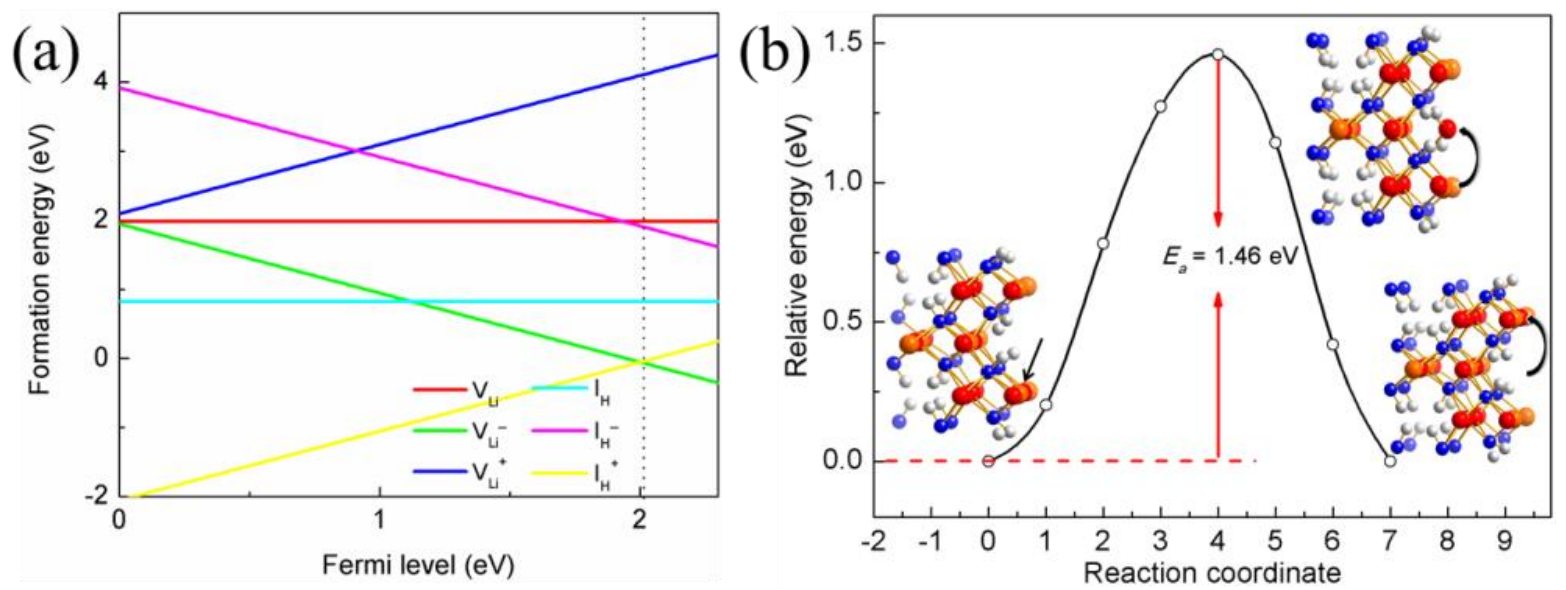

Figure 7. (a) Calculated formation energies for the charged hydrogen interstitial $\left(\mathrm{H}_{\mathrm{i}}\right)$ and lithium vacancy $\left(\mathrm{V}_{\mathrm{Li}}\right)$. $\mathrm{V}_{\mathrm{Li}}$ corresponds to removing a $\mathrm{Li}$ ion from pristine $\mathrm{Li}_{2} \mathrm{Mg}(\mathrm{NH})_{2}$, and $\mathrm{H}_{\mathrm{i}}$ corresponds to adding a $\mathrm{H}$ ion to form $\mathrm{NH}_{2}$ units. (b) Energetic profiles for the low-energy diffusion pathway of $\mathrm{V}_{\mathrm{Li}}{ }^{-}$in $\mathrm{Li}_{2} \mathrm{Mg}(\mathrm{NH})_{2}$. 